\title{
Review: bupropion and nortriptyline each increase smoking cessation rates
}

Hughes JR, Stead LF, Lancaster T. Antidepressants for smoking cessation. Cochrane Database Syst Rev 2004;(4):CD000031.

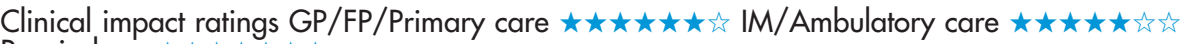

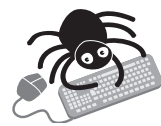

This article contains extra text on the EBM website

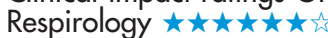

Do antidepressants increase long-term abstinence from smoking?

\section{METHODS}

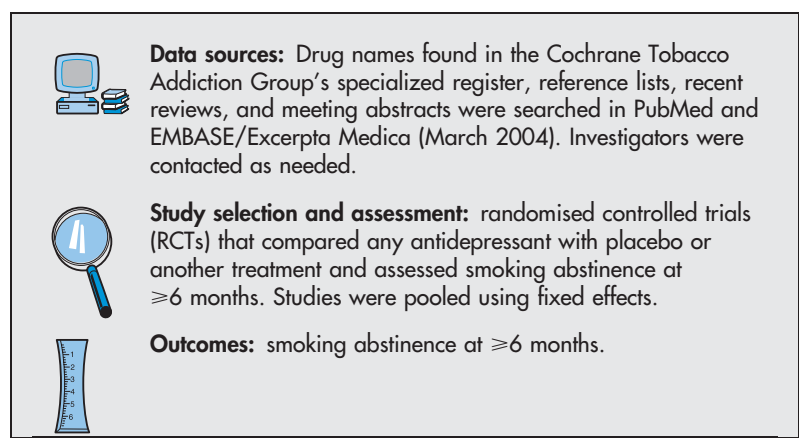

\section{MAIN RESULTS}

36 RCTs met the selection criteria. Tricyclic antidepressants. Nortriptyline increased smoking cessation; when added to nicotine replacement therapy (NRT), nortriptyline did not increase abstinence rates more than NRT alone (see table at www.evidencebasedmedicine.com). Monoamine oxidase inhibitors. Moclobemide did not show a statistically significant difference in abstinence at 12 months (see table at www.evidence-basedmedicine.com). Atypical antidepressants. Bupropion increased smoking cessation more than placebo (table). In smokers who had quit, bupropion did not prevent relapse more than placebo (see table at www.evidencebasedmedicine.com). Bupropion plus NRT increased smoking cessation more than NRT alone in I RCT but not in another unpublished RCT (table). I RCT showed that bupropion increased smoking cessation more than NRT (table). No statistically significant difference existed between bupropion and nortriptyline. Venlafaxine did not increase abstinence rates relative to placebo (see table at www.evidence-basedmedicine.com). Selective serotonin reuptake inhibitors (SSRIS). 5 RCTs (3 of fluoxetine, 1 of paroxetine, and 1 of sertraline) showed that SSRIs did not increase abstinence at $\geqslant 6$ months (see table at www.evidence-basedmedicine.com).

\section{CONCLUSIONS}

Bupropion and nortriptyline increase smoking cessation at $\geqslant 6$ months. Selective serotonin reuptake inhibitors do not increase abstinence. For correspondence: Professor $\mathrm{J}$ Hughes, University of Vermont, Burlington, VT, USA. john.hughes@uvm.edu

Sources of funding: National Institute on Drug Abuse and NHS Research and Development Programme.
Abstract and commentary also appear in ACP Journal Club.

Commentary

A ntidepressants for smoking cessation are of interest because of the higher rate of depression among smokers than non-smokers, the occurrence of depression in some smokers after they quit, and the interaction of nicotine and antidepressants with similar brain chemical systems. The detailed review by Hughes et al showed that only bupropion and, to a lesser extent, nortriptyline have strong evidence for effectiveness. SSRIs are not effective. All of these agents are useful for treatment of depression, which suggests that different neurochemical actions contribute to success in smoking cessation and that this success is not simply the result of treating subclinical depression. Both bupropion and nortriptyline interact with the dopamine and norepinephrine systems in the brain whereas SSRIs do not, which may account for the difference in efficacy.

An important question relates to the cost effectiveness of antidepressants. Any intervention that increases smoking cessation rates has favourable cost effectiveness because of the many years of life saved by quitting smoking. So one would anticipate that bupropion would be cost effective. Bupropion and nicotine patches had the most favourable profile in a recent analysis (cost per year of life saved of \$2214 and \$3901 for a man 50 and 54 y of age, respectively). ${ }^{1}$ An analysis based on a US RCT found an even lower cost per year of life saved for men 50-59 years of age (\$879). ${ }^{2}$ Nortriptyline has not been analysed in detail, but it is available generically. This potential advantage may be counteracted by the need for closer medical monitoring and more frequent dispensing of smaller quantities to limit the risk for overdose. Overall, use of antidepressants for smoking cessation is a significant advance in helping patients because it gives more options for treatment, both initially and for retreatment. Bupropion is approved by the Food and Drug Administration for smoking cessation and has the most effectiveness data, so it remains first line treatment along with the various forms of NRT. Nortriptyline should be a second line agent because it has been studied less and has the potential for serious side effects. Success in smoking cessation often requires several attempts, and clinicians now have a relatively wide range of agents to choose from to maximise patients' ability to quit.

Allan V Prochazka, MD, MSc Denver VA Medical Center Denver, Colorado, USA

1 Cornuz J, Pinget C, Gilbert A, et al. Eur J Clin Pharmacol 2003;59:201-6.

2 Javitz HS, Swan GE, Zbikowski SM, et al. Am J Manag Care 2004;10:217-26.

Antidepressants for increasing smoking cessation rates at $\geqslant 6$ months*

\begin{tabular}{|c|c|c|c|c|}
\hline Comparisons & No of comparisons & Event rates & RBI $(95 \% \mathrm{Cl})$ & NNT (Cl) \\
\hline $\begin{array}{l}\text { Nortriptyline vs placebo } \\
\text { Bupropion } v \text { placebo } \\
\text { Bupropion }+ \text { NRT } v \text { placebo }+ \text { NRT } \\
\text { Bupropion } v \text { NRT }\end{array}$ & $\begin{array}{r}4 \\
19 \\
1 \\
1\end{array}$ & $\begin{array}{l}17 \% \vee 7.0 \% \dagger \\
19 \% \vee 10 \% \dagger \\
22 \% \vee 9.8 \% \\
18 \% \vee 9.8 \%\end{array}$ & $\begin{array}{r}146 \%(58 \text { to } 281) \\
83 \% \text { (61 to } 108) \\
128 \%(46 \text { to } 256) \\
88 \%(18 \text { to } 198)\end{array}$ & $\begin{array}{r}10(7 \text { to } 17) \\
12(9 \text { to } 15) \\
8(6 \text { to } 17) \\
12(7 \text { to } 50)\end{array}$ \\
\hline
\end{tabular}

*NRT = nicotine replacement therapy. Other abbreviations defined in glossary; weighted event rates, NNT, and Cl calculated from data in article using a fixed effects model.

†Event rates are weighted. 